\title{
Reducing Computer Anxiety in Self-Paced Technology Training
}

\author{
Saurabh Gupta \\ Kennesaw State University \\ s.gupta@kennesaw.edu
}

\begin{abstract}
Industry reports continue to highlight the importance and growth of e-learning. However, researcher, trainers and trainees all agree that $e$ learning is different in terms of the level of personalization and anxiety that it brings, and its impact on outcomes. This paper presents a research model to reframe the dominant theory in technology training, i.e. Socio-Cognitive theory and its impact on learning, including the impact of perceived anxiety and teambased learning. Results from an empirical study are presented. Results show that teams based e-learning can reduce perceived anxiety and thus, improve training outcomes. Theoretical and practical implications are also presented.
\end{abstract}

\section{Introduction}

Training within organizations is one of the most pervasive methods for enhancing productivity of individuals and communicating organizations' goals to new personnel. In 2012, U.S. organizations with 100 or more employees spent $\$ 164.2$ billion on formal training [1]. Increasingly, much of this training is done through new training methods such as technology-mediated learning (TML). TML, also referred to as e-learning, is "an environment in which the learner's interactions with learning materials, peers, and/or instructor are mediated through advanced information technology" [2].

By 2009, it was estimated that $60 \%$ of core business processes and software included an TML component [3]. Dominant among this from of training is technology / end-user software training [1]. These technology training e-learning modules are generally self-paced, using multimedia demonstrations.

In spite of this rapid pace of adoption, researchers, trainers, educators and students have argued that online technology training is different in its nature of delivery and reaction of participants. While individuals generally work on online learning alone and have the advantage of quickly tracking their progress as they go along; a comparison of online learning with traditional face-toface classes shows that online learning students have higher anxiety [4]. Research, though limited, shows that higher levels of anxiety has had a detrimental effect on learning outcomes [5]. Researchers and educators are thus, constantly looking at ways to reduce anxiety levels among students as well as trying to see the impact of such reduction on learning outcomes.

Another major concern in using TML though has been the depersonalization of the training experience. Participants have a tendency of feeling lost and alone in this experience [6]. An emerging area of aimed at remedying this is using team-based learning in training [7]. In a comparison in education literature of e-learning with traditional classroom learning, researchers found that a collaborative approach increases student involvement in the course and the level of critical and active thinking, promotes problem-solving skills and increase's student satisfaction [8]. This is also true for technology training in classrooms, where collaboration has been shown to improve training outcomes and reduce anxiety [9].

However, three major gaps still exist within the literature. First, the dominant theory used in technology training is the social cognitive theory. Much of the research using this theory, though, has been on behavioral modeling, ignoring the other input stimuli, including perceived anxiety. Research presented in this paper uses all the elements of social cognitive theory, including verbal persuasion and psychological state, to couch the research framework. Second, much of the discussion regarding using collaboration in online technology training has been atheorticial in nature [10]. Consequently, the relationship between peercollaboration and self-anxiety remains unclear. Much of the focus of research has been on the relationship between collaborative methods and learning outcomes, rather than on anxiety. Research presented in this paper focuses on collaboration as a mechanism to reduce anxiety, and it's effect on learning outcomes. Finally, almost all the research regarding collaboration has been in face-to-face traditional scenarios. This research analyzes collaboration in a self-paced online technology training scenario; an area lacking in team based research (summarized in [11]) and Education ([12]) .

The research presented here aims to address all three of these gaps. It presents a theoretical model for online 


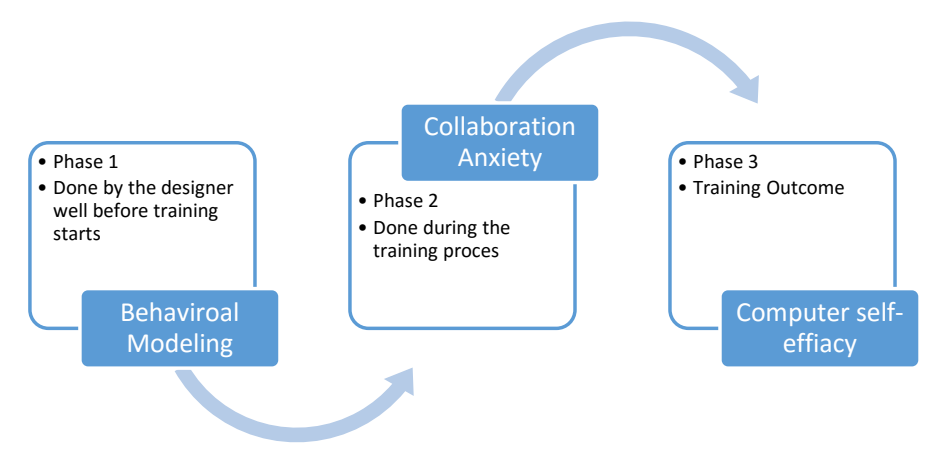

Figure 1: SCT Stimuli in Self-Paced online learning - Research Framework

technology training building on social cognitive theory as the differences that TML presents. It then reports the results a quasi-experiment examining the role of peercollaboration in behavioral modeling based online learning. The paper examines the impact of such collaboration on self-efficacy, satisfaction from the process, and anxiety.

The next section presents the research model, incorporating existing literature where appropriate. Next, we present the research methods and data analysis. Discussion regarding the results and its implications are presented last. We conclude by outlining the impact on future research.

\section{Literature Review and Research Model}

Most research in technology training outlines computer self-efficacy as the most important learning outcome. The construct is a combination of confidence and skill [13]. It has been argued to be the single biggest predictor of behavioral change in individuals [14]. Researchers, over the years, have also found it to be a good predictor of task performance [15]. Computer selfefficacy, a derivative of the general self-efficacy construct, is an individual's perception of one's ability to perform tasks using a computer [14]. Computer selfefficacy, specifically, has also been shown to have a positive effect on task outcomes, adoption as well as attitudes [16]. This, thus, is the core outcome construct that this research focuses on.

Social cognitive theory, used extensively in IS and Education research, is the most comprehensive conceptual approach to outlining the antecedents of selfefficacy [17]. Social cognitive theory postulates that training interventions as well as individual characteristics impact learning outcomes through reflection on observations.

\subsection{Sources of Self-Efficacy}

Social Cognitive theory outlines four major sources of self-efficacy enhancement: vicarious experience of observing the performances of others, enactive attainment, verbal persuasion and physiological state. Vicarious experience and enactive attainment, both dealing with using the end-user technology during training, are generally grouped together under behavioral modeling [18]. Verbal persuasion is the encouragement during the training process, while the physiological state deals primarily with the anxiety that the participants are experiencing [17].

Social Cognitive theory conceptualizes all four of these as similar inputs happening at the same time. Selfefficacy is conceptualized as the outcome. This inputoutput conceptualization was developed in the 80s. During the 80s, in a training context, all four stimuli were present at the same time. Enactive modeling and verbal persuasion are done simultaneously by the instructor while enactive learning is the practice that the students do in the presence of the instructor.

Self-paced online learning, on the other hand, has three distinct phases when each one of these stimuli are ether developed or present (see Figure 1). The first phase involves developing the training modules for online deployment. These are generally done separate from the training session, and at different times. It is important to recognize this difference, because all the feedback and content questions have to be anticipated before training is developed. Verbal persuasion, if implemented, is done during the collaboration process. This is also the phase when psychological states are influenced. The last phase, is the measurement of selfefficacy. Each of these stimuli is discussed further below.

Another important outcome construct analyzed is satisfaction from the process. Satisfaction, like selfefficacy, has been linked to multiple technology adoption [19], performance [20] and group outcomes [21]. In online learning environment, satisfaction from 
the process has been consistently used as an outcome variable as well [22, 23]. In this study, the learning process satisfaction is measured as a part of phase 3 .

2.1.1. Behavioral Modeling. The first two antecedents of self-efficacy deal with behavioral modeling, i.e. vicarious and / or enactive learning. Much of the EUT literature has focused on vicarious/behavioral modeling as a method of learning [24]. Vicarious modeling in previous research usually is done by using an instructor to demonstrate actions in a video. This learning method has been compared to lecture-based training, which uses the same content, but without demonstrations of content being taught. Social cognitive theory also emphasizes the role of self-modeling or enactive learning in a structured environment, with controls and feedback for knowledge enhancement. Enactive learning, builds on the modeling by doing self-modeling in a structured learning environment, with realistic feedback on actions and good guidance. It is focused on building cognitive knowledge models.

Most commercially available tools (such as Skillsoft, Microsoft's training, etc.) use modeling as the basis of all technology training. Trainees are shown videos with demonstrations of the end-user technology features. This is followed by a simulated environment where trainees can practice. Online training allows participants to use these training elements in self-paced environment, with the ability to repeat training modules as needed.

A consistent empirical finding is that modeling, both vicarious and enactive, leads to better training outcomes compared with other methods, such as lecture-based instruction or studying from a manual [24-27]. As hypothesized by the theory, empirical evidence supports the direct effect of modeling on computer self-efficacy enhancements in all environments.

In this research, we used existing tools to training participants in an end-user technology. However, instead of replicating the research with a focus on the effectiveness of behavioral modeling, this research focuses on the other two antecedents of self-efficacy (psychological state and verbal persuasion); especially in a self-paced technology-mediated environment.

2.1.2. Psychological State. Stressful and taxing situations generally elicit emotional arousal that, depending upon the circumstances, might have informative value concerning personal competency. Therefore, emotional arousal is another constituent source of information that can affect perceived selfefficacy in coping with complex and/ difficult situations. Measured as the perceived anxiety, this construct has been of consistent interest in technology training [28-31]. Although much of the research has been done in traditional environments, researchers have all highlighted the importance of this construct as an outcome, as well as its importance of a stimulus to selfefficacy.

Online technology training generally introduces two new elements: a) the instructional technology used and b) the end-user technology being trained on; creating complex situations. Existing research shows that students using online instructional technology exhibit more anxiety than traditional students, especially when dealing with complex topics [4]. Individuals who are especially susceptible to anxiety arousal readily become self-preoccupied with their perceived inadequacies in the face of difficulties rather than with the task at hand. For example, researchers have shown how increased anxiety can result in reduction in usage of learning structures (such as email), consequently reducing learning outcomes [5]. Similar results can be found in other studies using technology training in online environment, which outline how anxiety influences the task process [30]. However, most research, in a technology training context, has looked at self-anxiety assessments as an outcome to the learning process, instead of as an antecedent to self-efficacy [28]. In this research, we examine anxiety as an antecedent to computer self-efficacy. Thus, consistent with SCT, we hypothesize the following.

H1: Extent of perceived self-anxiety will have a negative effect on computer self-efficacy in an online learning environment.

Another important psychological state part of the learning process is satisfaction from the process. Satisfaction from the process is how well the participant enjoyed or found the process to be reasonable. The more satisfied the process, the more engaged the trainer is likely to be; which in turn affect's self-efficacy.

H2: Extent of satisfaction from the learning process will have a positive effect on computer self-efficacy in an online learning environment.

2.1.3. Verbal Persuasion. Learning is complex, involving challenging activities. Verbal persuasion is widely used to try to talk to people into believing they possess capabilities that will enable them to achieve what they seek. These can be through suggestion, exhortation, self-instruction or interpretive treatments. People are led, through suggestion, into believing they can cope successfully with what has overwhelmed them in the past.

In the face of complex or difficult learning objectives or where there is a long history of failure when learning, behavioral modeling influence can be 
readily extinguished by disconfirming experiences. This is where verbal persuasion can help by explaining the learning method better or providing verbal scaffolds for the learning process.

The interaction that leads to verbal persuasion can be of two types 1) between trainer and trainees and 2) between trainees. In a face-to-face training situation, the interaction between trainer and trainees is done as a normal part of the process. Although SCT does not distinguish between these two kinds of interaction, it does theorize that such interaction is focused directly on skill and confidence enhancement - the two critical elements of self-efficacy.

Much of the discussion regarding verbal persuasion in technology training has been done in a face-to-face situation; relaying primarily on instructor-trainee interaction [16]. Studies have primarily focused on feedback, either as task feedback [32] or explaining the content by the instructor orally [33] or written [34]. Such feedback may or may not contain encouragement; a key tenant of verbal persuasion. Only one study has focused directly on encouragement and its direct effect on self-efficacy [13]. This study focused on encouragement outside the learning environment, such as supervisors, friends and family. None of these studies found a strong, direct impact of such as instructor driven feedback on self-efficacy.

A second form of interaction is between peers. This form of interaction, i.e. trainee-to-trainee interaction has received limited attention in practice and research. Online technology training has been viewed as an individualistic product, done in a self-paced manner at an individual's convenience. More recently though, researchers and commercial products are starting to introduce collaborative online learning, either through the addition of paired learning environments or through asynchronous discussion forums. The goal here is to enhance collaboration between trainees. However, no research that we know of has looked at this interaction in an online training environment for technology training.

Outside online learning, a meta-analysis examining various collaboration techniques suggests that collaboration does have a positive impact in general higher-education settings [35], end-user declarative knowledge [10] as well as peer programing [36]. Only three studies that we know of have investigated collaboration in technology training. Two of these did not find a direct effect on self-efficacy [9, 37] while one did [38].

In this study, we use teams of dyads going through an online training together. The experimental controls allow them to interact, while the experiment protocol forces each of the dyad members to ask each other at least three questions that they need help on. Thus, not only is the opportunity for interaction between trainees provided, tenants of verbal persuasion interaction between trainees are also enforced. While previous empirical evidence is inconclusive, we hypothesize the following based on the underlying SCT theory.

H3: Extent of collaboration will have a positive impact on Computer Self-Efficacy in an online technology training environment.

The second outcome variable is satisfaction from the learning process. While research in group decision support system literature shows that team work increases satisfaction [21]; results in education using discussion boards in online class have not found any difference [22]. However, drawing on the theory, we hypothesize.

H4: Extent of collaboration will have a positive impact on satisfaction from the learning process in an online technology training environment.

2.1.4. Theory Extension. Social cognitive theory takes an input-output view. The four influences are viewed as inputs while self-efficacy is the output. The processes through which these influences work are argued to be cognitive in nature. In a self-paced online technology training, these inputs are not all presented at the same time. Behavioral modeling, including demonstration, simulation and feedback, are all prebuilt by the instructor beforehand.

The two other input constructs, i.e. psychological state and verbal persuasion have a temporal distance between them. Psychological state (anxiety in this case) and Verbal persuasion (peer cohesion in this case) are measured as a part of the learning process. Consequently, we argue that assuming all the inputs to have the same path is not correct.

Social Cognitive theory conceptualizes a direct impact of verbal persuasion on self-efficacy. In a learning/training context, much of this is based on the argument that encouragement and support by the instructor are helpful in enhancing confidence of the learner/trainee, a critical component of self-efficacy. In a self-paced online technology training context though, this continuous support and encouragement from the trainer are missing because of the nature of the delivery. The training software can be built in one location (or organization) by an instructor /trainer and implement in a different location (or organization) without any involvement by the instructor. In an online self-paced training environment, the interactions between trainee and trainer are pre-built into the system through the use of feedback and help. 
However, as mentioned earlier, the second type of interaction, i.e. peer-to-peer, is also gaining prominence in self-paced online technology training in both practice and research. We argue that such interaction is not directly focused on enhancing skill or confidence of the task at hand. Instead, this interaction brings in the ability to relate to material. Trainees also draw on each other's experience as a part of this interaction. Research shows that greater the computer experience, the lower the computer self-anxiety [28]. We argue that this is true even when the experience is vicariously drawn i.e. through trainee-trainee interaction. Aversive stimuli though interaction of peers relaxes trainees, reducing the levels of anxiety driven defensive behaviors. Only one study that we know of investigated the impact of peer collaboration on self-anxiety and found a positive impact [9]. This study, though, was done in a face-toface context. Thus, we hypothesize.

H5: Extent of collaboration will have a negative impact on Computer Self-Anxiety in an online technology training environment.

\section{Research Method}

The data collected for this paper came from an empirical study conducted with students in an Introduction to MIS class at a leading south-eastern university. The end-user tool used was Excel. Students were learning basic Excel as well as basic Excel Graphs. The initial sample was 135 students. Students were

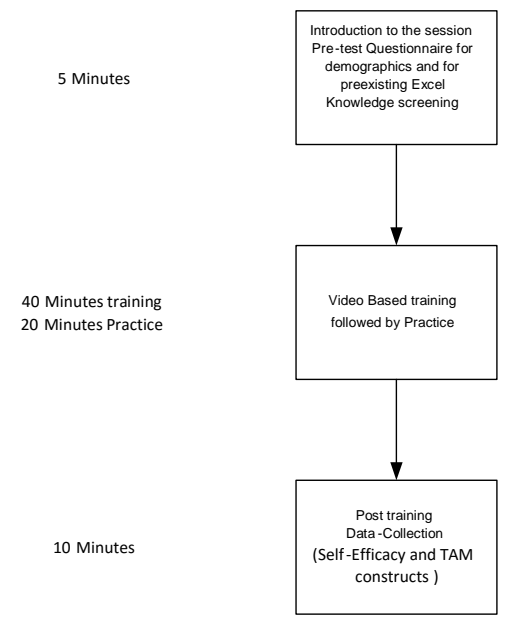

Sample : Introduction to MIS undergraduate business class Initial Sample : 135 Final Sample : 119

Figure 2: Experimental Procedure given course credit for participation. Students with any Excel experience, as tested using a quiz containing procedural and declarative knowledge questions (25\% or more on the quiz), were eliminated. Due to possible confounding effects [39], students were asked to report any previous e-learning experience and were eliminated from the final sample if they did. The final sample size was 119 . The sample did not show any statistical differences between genders (61 females, 58 males) or business majors. The average CGPA was 3.34. The training lasted 1.25 hours and dealt with cell references and formulas. Figure 2 shows the experimental procedure.

Students were trained in Excel using commercially available technology-mediated training method. The tool contained a video demonstration (vicarious training), followed by simulated sessions for enactive learning. It was selected because it included features that implemented vicarious and enhanced enactive learning. The tool is designed based on industry best practices and accepted instructional design principles. As mentioned earlier, empirical research shows this as the best method for technology training. In addition, the product has gained large acceptance in universities and organizations alike to train trainees, providing realism to the quasi-experiment. Post training, the participants were asked to fill in a single questionnaire containing item's measuring cohesion, perceived anxiety, selfefficacy and satisfaction. All data was gathered at the individual level. An overview of the experimental design is provided in Figure 2. The following instruments were used to measure each of the constructs. All instruments used came from existing literature.

Collaboration: Dyads have been shown to be popular in education and in peer programing [40, 41]. Thus, in this study, participants were put in dyads. All groups were zero-history groups. A popular measure of how well group "gels" together is cohesion [42, 43]. It is often described as the psychological force that binds people together [44]. Researchers have shown that higher level of cohesion plays an additive role in improving group outcomes [42, 45, 46]. The five-item Seashore Index of Group Cohesiveness, as modified in Chidambaran, Bostrom [47], was used. The reliability was acceptable in their study (alpha $=0.89$ ). It has been used in previous IS research as well [48].

Perceived Anxiety: Computer anxiety was measured using four items drawn from the Computer Anxiety Rating Scale [49]. The reliability of this instrument in that study was 0.87 (alpha). The scale has been used in other IS studies as well [50].

Satisfaction: A five item scale from Green et al. [51], $\alpha=0.88$, was used to measure the satisfaction of the individual with the process. 
Computer Self-efficacy: In the current study, the focus was on self-efficacy of Excel technology. The measure used was developed by Hollenbeck et al. [52], $\alpha=0.89$ (used in EUT by Martocchio [53]) and Gupta and Bostrom [38]).

\subsection{Data Analysis and Results}

Data collected was analyzed with PLS using SmartPLS 3. The first step was to analyze the data for validity and reliability. PLS offers several advantages over other methods such as a more robust results set, more accurate predictions, accommodates correlations among independent latent variables better [54], and higher acceptance \& compatibility with in/other IS studies.

Reliability: The first one to check is Indicator Reliability. It can be seen that all the indicators have individual indicator reliability values that are much larger than the minimum acceptable level of 0.7. Traditionally, "Cronbach's alpha" is used to measure internal consistency reliability in social science research, but it tends to provide a conservative measurement in PLS-SEM. Prior literature has suggested the use of "Composite Reliability" as a replacement $[55,56]$. In Table 1 , all values are shown to be larger than 0.6, so high levels of internal consistency reliability have been demonstrated among all three reflective latent variables. However, for continuity research perspective, Cronbach's alpha is also reported Table 1.

Table 1: Latent Construct Reliability

\begin{tabular}{|c|c|c|c|c|c|c|}
\hline $\begin{array}{l}\text { Latent } \\
\text { Construct }\end{array}$ & Indicators & Loadings & $\begin{array}{l}\text { Indicator } \\
\text { Reliability }\end{array}$ & $\begin{array}{l}\text { Composite } \\
\text { reliability }\end{array}$ & $\begin{array}{l}\text { Cronbach's } \\
\text { Alpha }\end{array}$ & AVE \\
\hline \multirow[t]{3}{*}{ Cohesion } & B_COHE_B & 0.953 & 0.908 & \multirow{3}{*}{0.971} & \multirow{3}{*}{0.955} & \multirow{3}{*}{0.917} \\
\hline & $\mathrm{B}_{-} \mathrm{COHE}_{-} \mathrm{C}$ & 0.964 & 0.929 & & & \\
\hline & B_COHE_D & 0.955 & 0.912 & & & \\
\hline \multirow[t]{3}{*}{ Satisfaction } & B_SATIS1 & 0.837 & 0.702 & \multirow{3}{*}{0.887} & \multirow{3}{*}{0.813} & \multirow{3}{*}{0.724} \\
\hline & B_SATIS2 & 0.891 & 0.793 & & & \\
\hline & B_SATIS4 & 0.872 & 0.760 & & & \\
\hline \multirow{4}{*}{$\begin{array}{l}\text { Computer } \\
\text { Self-Efficacy }\end{array}$} & B_SE1 & 0.846 & 0.717 & \multirow[t]{4}{*}{0.852} & \multirow[t]{4}{*}{0.791} & \multirow{4}{*}{0.591} \\
\hline & B_SE2_R & 0.865 & 0.749 & & & \\
\hline & B_SE3 & 0.837 & 0.700 & & & \\
\hline & B_SE4_R & 0.876 & 0.768 & & & \\
\hline \multirow{3}{*}{$\begin{array}{l}\text { Perceived } \\
\text { Anxiety }\end{array}$} & B_SSANX1 & 0.858 & 0.736 & \multirow{3}{*}{0.924} & \multirow{3}{*}{0.877} & \multirow{3}{*}{0.803} \\
\hline & B_SSANX2 & 0.904 & 0.817 & & & \\
\hline & B_SSANX3 & 0.924 & 0.853 & & & \\
\hline
\end{tabular}

Validity: To check convergent validity, each latent variable's Average Variance Extracted (AVE) is evaluated. Again from Table 1, it is found that all of the AVE values are greater than the acceptable threshold of 0.5 , so convergent validity is confirmed. Fornell and Larcker [57] suggest that the square root of AVE in each latent variable can be used to establish discriminant validity, if this value is larger than other correlation values among the latent variables. Sqrt AVE's are reported in the diagonal of the Table 2 . The correlations between the latent variables are reported in the other cells.
Table 2: Correlation and Sqrt(AVE)

\begin{tabular}{|l|r|r|r|l|}
\hline Latent Construct/sqrt(AVE) & \multicolumn{1}{l|}{ Cohesion } & \multicolumn{1}{l|}{ Satisfaction } & \multicolumn{1}{l|}{ Self-efficacy } & \multicolumn{1}{l|}{ self-anx } \\
\hline Cohesion & 0.957 & & & \\
\hline Satisfaction & -0.209 & 0.850 & & \\
\hline Self-efficacy & 0.122 & -0.249 & 0.768 & \\
\hline self-anx & -0.140 & 0.173 & -0.374 & 0.896 \\
\hline
\end{tabular}

Subsequently, the two structural models were run using bootstrapping. The first, modeled cohesion with a direct effect on computer self-efficacy and satisfaction. Anxiety was also modeled to have a direct effect on computer self-efficacy. Both constructs had a significant impact. In the second model, as shown in Figure 3, Cohesion was modeled to have a direct and indirect effect (through anxiety) on computer selfefficacy. In this case, all paths shown were significant, except for the direct effect of cohesion on computer selfefficacy. This confirms that that cohesion has an indirect effect rather than a direct effect.

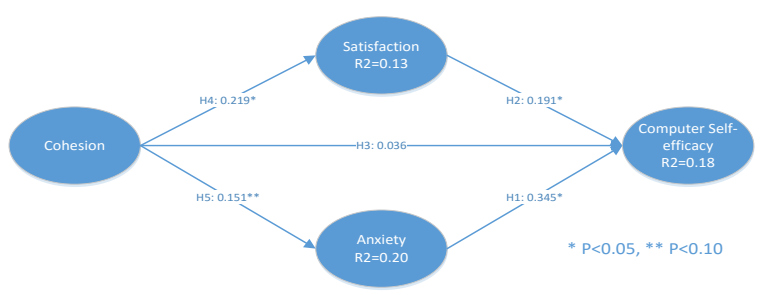

Figure 3: Research Model and SEM Results

\section{Limitations}

Limitations of the study stem primarily from the context of the study and the nature of the research method. The concerns about the limitations of a quasiexperiment study have been well-documented [58]. While efforts were made to make the context as representative of organizations and a realistic representation of a university environment, the focus of the study has been on enhancing the internal validity of the study. In addition, the TML technology used was highly representative of the technology used in university and corporate environments.

\section{Discussion and Conclusion}

As mentioned earlier, the three important influencers to computer self-efficacy in this study are behavioral modeling, group cohesion and anxiety. Secondary outcome used was satisfaction from learning process, since this is an important variable of interest in online education. The model explains $20 \%$ level of regression 
in computer self-efficacy. The hypothesis results are summarized in Table 3.

Behavioral modeling principles were used to select the right instructional tool. The core principles of vicarious learning were implemented via video and principles of enactive modeling were implemented via a simulated practice session. The effectiveness of this has been well tested in previous literature and assumed in this study. Thus, no comparison with other methods was done.

Table 3: Hypothesis Results

\begin{tabular}{|c|c|c|c|c|c|}
\hline & Hypothesis & Path Mean & T Statistics & P Values & Supported \\
\hline & Anxiety -> Self-efficacy & -0.345 & 4.201 & 0.001 & Yes \\
\hline $\mathrm{H} 2$ & Satisfaction -> Self-efficacy & -0.191 & 2.496 & & Yes \\
\hline${ }^{14} 4$ & Cohesion $->$ Satisfaction & -0.219 & 2.34 & 0.02 & \\
\hline $\mathrm{H} 3$ & Cohesion $->$ Self-efficacy & 0.036 & 0.363 & 0.716 & \\
\hline $\mathrm{H} 5$ & Cohesion $>$ Anxiety & -0.151 & 1.751 & 0.081 & Yes \\
\hline
\end{tabular}

Anxiety was modeled to have direct influence on both outcomes: computer self-efficacy and satisfaction from the process. The study supports these hypotheses at $\mathrm{P}<0.05$ level. The path coefficients suggest that anxiety is a significant predictor of computer selfefficacy in an online environment. While this provides continued evidence to the robustness of social cognitive theory, it also provides support to the assertion that anxiety is an especially important construct in a selfpaced online technology training environment. The perceived level of anxiety also had a strong effect on the satisfaction from learning process. Both of these results taken together, suggest that online technology training environment should focus on reducing anxiety as a part of the learning process.

The final antecedent (tested in the study) to computer self-efficacy according to a social cognitive theory is verbal persuasion. The level of verbal persuasion was implemented via experimental procedures and measured using group cohesion. The study shows some interesting results here. First, there is no direct significant effect of cohesion on self-efficacy. This is contrary to the theory. Thus, the hypothesis is not supported. Secondly, and more importantly, the path coefficient between cohesion and anxiety is significant. Taken together, we argue that this is because of the context of the study, i.e. self-paced online technology training. Social Cognitive theory, conceptualized in the 1980's, did not have the benefit of an online education environment. In a traditional face-to-face environment, all the antecedents of self-efficacy are present at the same time. However, as shown in Figure 1, there is a temporal distance between when the antecedents are present. In addition, the focus of verbal persuasion in original SCT was the instructor, rather than on peers. Given this, we have argued and shown that peer verbal persuasion has an indirect influence on computer selfefficacy, rather than direct. Verbal persuasion is instrumental in reducing anxiety, which in turn influence's self-efficacy.

This finding has important implications on how collaboration should be viewed in self-paced online technology education. Much of the focus recently, has been on introducing elements of discussion boards, web 2.0 features, etc. to enhance collaboration. Group assignments or discussion boards focus on enhancement of content or student driven discussion boards. However, the results from this study suggest that collaboration in self-paced online education should not focus on content, but instead focus on reduction of anxiety, i.e. students sharing their perspective over the course, discussing and solving course-related problems; rather than presenting content from their perspective.

\section{Conclusions}

The core objective of the study was to move enduser training research beyond behavioral modeling, enchaining our ability to increase the effectiveness of training procedures. Overall, the study has four distinct implications for research and practice.

First, the study brings social cognitive theory to the modern era by applying it to self-paced online technology training context. The paper outlines how and why the elements of social-cognitive theory need to be reordered from an input-output perspective to include process. We argue that verbal persuasion and anxiety should be viewed as process variables. This is important because, as shown throughout this study, not all variables have a direct effect on learning outcomes.

Second, the paper outlines the need to focus on perceived anxiety in an online training context. Online training has been increasing in both business and academia. Much of the focus on of this research has been on content development. However, we argue that there needs to be a focus on perceived anxiety in these courses as well since a) anxiety is higher in online courses and b) anxiety has a strong correlation to learning outcomes (as shown in this study).

Third, this study recognizes the lack of verbal persuasion from trainers in self-paced online technology training context. However, the study outlines peercollaboration as an important mechanism for reducing perceived anxiety. This study shows that peercollaboration does not have a direct effect on learning outcomes, but instead is instrumental in reducing perceived anxiety. This suggests that the future focus of 
instructional designers and trainers in online technology training context needs to focus on using tools such as discussion boards, wikis and emails for anxiety reduction rather than enhancing learning content. This restructured focus of the discussion board towards anxiety reduction rather than content development, can be done asynchronously as well as persistently across multiple training modules and training individuals.

Finally, the overarching ideas of theory and design of self-paced online technology education can also be extended to other technical and quantitative disciplines. These disciplines suffer the similar levels of anxiety as end-user training. Peer-collaboration, especially, dyads can be used in these disciplines as well to reduce anxiety and enhance learning outcomes.

\section{References}

\section{[1.] ASTD, ASTD State of the Industry Report. 2012, ASTD.}

[2.] Alavi, M. and D.E. Liedner, Research Commentary: Technology-Mediated Learning--A Call for Greater Depth and Breadth of Research. Information Systems Research, 2001. 12(1): p. 1-10.

[3.] Gartner, Predicts 2005: Support Improves for Knowledge Workers. 2004, Gartner. p. 7-7.

[4.] DeVaney, T.A., Anxiety and attitude of graduate students in on-campus vs. online statistics courses. Journal of Statistics Education, 2010. 18(1): p. 1-15.

[5.] Fuller, R.M., C. Vician, and S.A. Brown, E-learning and individual characteristics: The role of computer anxiety and communication apprehension. The Journal of Computer Information Systems, 2006. 46(4): p. 103.

[6.] Moore, M.G. and G. Kearsley, Distance education: A systems view of online learning. 2011: Cengage Learning.

[7.] Alavi, M., B.C. Wheeler, and J.S. Valancich, Using IT to reengineer business education: An exploratory investigation of collaborative telelearning. MIS Quarterly, 1995. 19(3): p. 293-211.

[8.] Rohrbeck, C.A., et al., Peer-Assisted Learning Interventions With Elementary School Students: A MetaAnalytic Review. Journal of Educational Psychology, 2003. 95(2): p. 240-257.

[9.] Keeler, C. and R. Anson, An assessment of cooperative learning used for basic computer skills instruction in the college classroom. Journal of Educational Computing Research, 1995. 12(4): p. 379-393.

[10.] Gupta, S., R.P. Bostrom, and M. Huber, End-user training methods: What we know, Need to know. SIGMIS Database for Advances in Information Systems, 2010. 41(4): p. 9-39.

[11.] Gupta, S. and R.P. Bostrom, End-User Training: What we know, What we need to know? Database for Advances in Information Systems, 2010. 41(4): p. Forthcoming.
[12.] Lehtinen, E., et al., Computer supported collaborative learning: A review. 2003.

[13.] Compeau, D.R. and C.A. Higgins, Computer SelfEfficacy: Development of a Measure and Initial Test. MIS Quarterly, 1995. 19(2): p. 189-211.

[14.] Bandura, A., Self-efficacy: Toward a unifying theory of behavioral change. Psychological Review, 1977(84): p. pp. 191-215.

[15.] Gist, M.E. The effects of self-efficacy training on training task performance. in Academy of Management. 1986. Ada, $\mathrm{OH}$.

[16.] Compeau, D., et al., Computer self-efficacy: A review, in Human-Computer Interaction in Management Information Systems, D. Galletta and P. Zhang, Editors. 2005, M. E. Sharpe, Inc. p. 1-87.

[17.] Bandura, A., Social foundations of thought and action : a social cognitive theory. Prentice-Hall series in social learning theory. 1986, Englewood Cliffs, N.J.: Prentice-Hall. xiii, 617.

[18.] Johnson, R.D. and G.M. Marakas, Research Report: The Role of Behavioral Modeling in Computer Skills Acquisition-Toward Refinement of the Model. Information Systems Research, 2000. 11(4): p. 402-417.

[19.] Al-Gahtani, S.S. and M. King, Attitudes, satisfaction and usage: factors contributing to each in the acceptance of information technology. Behaviour \& Information Technology, 1999. 18(4): p. 277-297.

[20.] Organ, D., A Restatement of the SatisfactionPerformance Hypothesis. Journal of Management, 1988. 14(4): p. 547-557.

[21.] Reinig, B.A., Toward an Understanding of Satisfaction with the Process and Outcomes of Teamwork. Journal of Management Information Systems, 2003. 19(4): p. 65-84.

[22.] Cho, M.-H. and S. Tobias, Should Instructors Require Discussion in Online Courses? Effects of Online Discussion on Community of Inquiry, Learner Time, Satisfaction, and Achievement. The International Review of Research in Open and Distributed Learning, 2016. 17(2): p. 123-140.

[23.] Paul Jen-Hwa, H. and H. Wendy, Examining the role of learning engagement in technology-mediated learning and its effects on learning effectiveness and satisfaction. Decision Support Systems, 2012. 53: p. 782-792.

[24.] Gupta, S. and R.P. Bostrom. End-User Training: What we know, What we need to know? in SIGCPR MIS, ACM conference. 2006. Claremont, CA.

[25.] Bolt, M.A., L.N. Killough, and H.C. Koh, Testing the interaction effects of task complexity in computer training using the social cognitive model. Decision Sciences, 2001. 32(1): p. 1-20.

[26.] Davis, D.L. and D.F. Davis, The Effect of Training Techniques and Personal Characteristics on Training End Users of Information Systems. Journal of Management Information Systems, 1990. 7(2): p. 93-110. 
[27.] Yi, M.Y. and F.D. Davis, Developing and Validating an Observational Learning Model of Computer Software Training and Skill Acquisition. Information Systems Research, 2003. 14(2): p. 146-170.

[28.] Chua, S.L., D.T. Chen, and A.F.L. Wong, Computer anxiety and its correlates: a meta-analysis. Computers in Human Behavior, 1999. 15(5): p. 609-623.

[29.] Griffin, M.M. and B.W. Griffin, An Investigation of the Effects of Reciprocal Peer Tutoring on Achievement, SelfEfficacy, and Test Anxiety. Contemporary Educational Psychology, 1998. 23(3): p. 298-311.

[30.] Brosnan, M.J., The impact of computer anxiety and selfefficacy upon performance. Journal of Computer Assisted Learning, 1998. 14(3): p. 223-234.

[31.] McInerney, V., D.M. McInerney, and H.W. Marsh, Effects of Metacognitive Strategy Training Within a Cooperative Group Learning Context on Computer Achievement and Anxiety : An Aptitude-Treatment Interaction Study. Journal of Educational Psychology, 1997. 89(4): p. 686695.

[32.] Mitchell, T.R., et al., Predicting Self-Efficacy and Performance During Skill Acquisition. Journal of Applied Psychology, 1994. 79(4): p. 506-517.

[33.] Compeau, D.R. and C.A. Higgins, Application of Social Cognitive Theory to Training for Computer Skills. Information Systems Research, 1995. 6(2): p. 118-143.

[34.] Martocchio, J.J. and J. Webster, Effects of feedback and cognitive playfulness on performance in microcomputer software training. Personnel Psychology, 1992. 45(3): p. 553578 .

[35.] Johnson, D.W., R.T. Johnson, and M.B. Stanne, Cooperative Learning Methods: A Meta-Analysis. 2000.

[36.] Salleh, N., E. Mendes, and J. Grundy, Empirical studies of pair programming for CS/SE teaching in higher education: a systematic literature review. IEEE Transactions on Software Engineering, 2011(4): p. 509.

[37.] Davis, F.D. and M.Y. Yi, Improving Computer Skill Training: Behavior Modeling, Symbolic Mental Rehearsal, and the Role of Knowledge Structures. Journal of Applied Psychology, 2004. 89(3): p. 509-523.

[38.] Gupta, S. and R.P. Bostrom, An Investigation of the Appropriation of Technology-Mediated Training Methods Incorporating Enactive and Collaborative Learning. Information Systems Research, 2013. 24(2): p. 454-469.

[39.] Wang, C.-H., D.M. Shannon, and M.E. Ross, Students' Characteristics, Self-Regulated Learning, Technology SelfEfficacy, and Course Outcomes in Online Learning. Distance Education, 2013. 34(3): p. 302-323.

[40.] Lou, Y., P.C. Abrami, and S. d'Apollonia, Small group and individual learning with technology: A meta-analysis. Review of Educational Research, 2001. 71(3): p. 449-521.

[41.] Lou, Y., et al., Within-class grouping: A meta-analysis. Review of Educational Research, 1996. 66(4): p. 423-458.
[42.] Gully, S.M., D.J. Devine, and D.J. Whitney, A MetaAnalysis of Cohesion and Performance: Effects of Level of Analysis and Task Interdependence. Small Group Research, 2012. 43(6): p. 702-725.

[43.] Beal, D.J., et al., Cohesion and Performance in Groups: A Meta-Analytic Clarification of Construct Relations. Journal of Applied Psychology, 2003. 88(6): p. 989-1004.

[44.] Keyton, J. and J. Springston, Redefining Cohesiveness in Groups. Small Group Research, 1990. 21(2): p. 234-254.

[45.] Langfred, C., Is Group Cohesiveness a Double-Edged Sword? An Investigation of the Effects of Cohesiveness on Performace. Small Group Research, 1998. 29(1): p. 124-143.

[46.] Yoo, Y. and M. Alavi, Media and Group Cohesion: Relative Influences on Social Presence, Task Participation, and Group Consensus. MIS Quarterly, 2001. 25(3): p. 371390.

[47.] Chidambaran, L., R.P. Bostrom, and B.E. Wynne, A Longitudinal Study of the Impact of Group Decision Support Systems on Group Development. Journal of Management Information Systems, 1991. 7(3): p. 7-26.

[48.] Anson, R., R.P. Bostrom, and B. Wynne, An experiment assessing Group Support System and facilitator effects on meeting outcomes. Management Science, 1995. 41(2): p. 189208.

[49.] Heinssen, J.R.K., C.R. Glass, and L.A. Knight, Assessing computer anxiety: Development and validation of the Computer Anxiety Rating Scale. Computers in Human Behavior, 1987. 3(1): p. 49-59.

[50.] Thatcher, J.B. and P.L. Perrewe, An emperical examination of individual traits as antecedents to comptuer anxiety and computer self-efficacy. MIS Quarterly, 2002. 26(4): p. 381-397.

[51.] Green, S.G. and T.D. Taber, The effects of three social decision schemes on decision group process. Organizational Behavior and Human Performance, 1980. 25: p. 97-106.

[52.] Hollenbeck, J.R. and A.P. Brief, The effects of individual differences and goal origin on goal setting and performance. Organizational Behavior and Human Decision Processes, 1987. 40: p. 392-414.

[53.] Martocchio, J.J., Effects of Conceptions of Ability on Anxiety, Self-Efficacy, and Learning in Training. Journal of Applied Psychology, 1994. 79(6): p. 819-826.

[54.] Cramer, R.D., Partial Least Squares (PLS): Its strengths and limitations. Perspectives in Drug Discovery and Design, 1993. 1(2): p. 269-278.

[55.] Bagozzi, R.P., Y. Yi, and L.W. Phillips, Assessing Construct Validity in Organizational Research. Administrative Science Quarterly, 1991. 36(3): p. 421-458.

[56.] Hair, J.F., et al., A primer on partial least squares structural equations modeling (PLS-SEM). 1st ed. 2013: Ringgold, Inc.

[57.] Fornell, C. and D.F. Larcker, Evaluating Structural Equation Models with Unobservable Variables and 
Measurement Error. 1981, American Marketing Association. p. 39-50.
[58.] Campbell, D.T., J.C. Stanley, and N.L. Gage, Experimental and quasi-experimental designs for research. 1966, Chicago,: R. McNally. ix, 84. 